\title{
Corrigendum
}

\section{Peripheral arterial catheter colonization in cardiac surgical patients - CORRIGENDUM}

Regarding the above mentioned article by Levinson et $\mathrm{al}^{1}$, the authors would like to acknowledge the following correction:

In our article entitled "Peripheral arterial catheter colonization in cardiac surgical patients," we stated that arterial catheter insertion in the operating room was carried out using alcoholic chlorhexidine and small sterile drape. We have determined that there is variability in arterial catheter insertion practice in our operating rooms as some catheters are inserted without a sterile drape and some with use of alcohol alone for cutaneous antisepsis.

\section{Reference}

1. Levinson AT, Chapin KC, LeBlanc L, Mermel LA. Peripheral arterial catheter colonization in cardiac surgical patients. Infection Control Hosp Epidemiol 2018;40:1008-1009. 